\title{
Crescimento radicular e pigmentos clorofilianos em duas forrageiras submetidas a níveis crescentes de $\mathrm{NaCl}$
}

\author{
Root growth and chlorophyll pigments in two forages subjected to increasing \\ levels of $\mathrm{NaCl}$
}

\begin{abstract}
Andressa Freitas de Lima RHEIN ${ }^{1}$; Flávio José Rodrigues CRUZ $^{2}$; Rener Luciano de Souza FERRAZ³ Durvalina Maria Mathias dos SANTOS ${ }^{4}$

1 Eng. Agr., MSc., Dra. em Agronomia - Agricultura, UNESP-FCA, Faculdade de Ciências Agronômicas - Fazenda Experimental Lageado - Rua José Barbosa de Barros, no 1780 - CEP 18610-307, Botucatu - SP, e-mail: andressa_rhein@yahoo.com.br;

${ }^{2}$ Eng. Agr., MSc., Dr. em Agronomia - Produção Vegetal, UNESP-FCAV, via de acesso Prof. Paulo Donato Castellane, s/n, CEP 14884-900, Jaboticabal-SP, e-mail: fjrc@bol.com.br;

${ }^{3}$ Autor para correspondência, Lic., MSc. em Ciências Agrárias, Doutorando em Agronomia - Produção Vegetal, Universidade Estadual Paulista, Faculdade de Ciências Agrárias e Veterinárias, Departamento de Biologia Aplicada à Agropecuária, Laboratório de Fisiologia Vegetal, via de acesso Prof. Paulo Donato Castellane, s/n, CEP 14884-900, Jaboticabal-SP, e-mail: ferraz340@gmail.com;

${ }^{4}$ Bióloga, Livre Docente, Prof. Adjunto do Departamento de Biologia Aplicada à Agropecuária, UNESP-FCAV, via de acesso Prof. Paulo Donato Castellane, s/n, CEP 14884-900, Jaboticabal-SP, e-mail: dumaria@fcav.unesp.br
\end{abstract}

Recebido em: 17-08-2014; Aceito em: 22-06-2015

\section{Resumo}

A salinidade representa um obstáculo ao cultivo agrícola em regiões onde é abundante a concentração de sais minerais, em particular aqueles que contêm os íons $\mathrm{Na}^{+}$e $\mathrm{Cl}^{-}$. Objetivou-se com este estudo avaliar o crescimento radicular e os teores de pigmentos clorofilianos de duas leguminosas forrageiras cultivadas na presença de níveis crescentes de salinidade. O experimento foi conduzido em sala de crescimento com condições de temperatura e luminosidade controladas. A semeadura foi realizada em bandejas preenchidas com areia estéril umedecida. Transcorridos 10 dias após a semeadura, as plântulas foram transplantadas para vasos com solução nutritiva. O delineamento experimental empregado foi 0 inteiramente casualizado, em esquema fatorial (2x6), com seis repetições. Os tratamentos consistiram em duas forrageiras (guandu cv. Caqui e labe-labe cv. Rongai) e seis concentrações de $\mathrm{NaCl}(0 ; 20 ; 40 ; 60 ; 80$ e $120 \mathrm{mM})$, em solução nutritiva. Foram avaliados a densidade e a fitomassa radicular, e os teores de clorofila 'a', 'b', total e relação a/b. Os dados foram submetidos à análise de variância, teste de médias e regressão polinomial. Entre as forrageiras avaliadas, o labe-labe cv. Rongai expressou maior crescimento radicular e teores de pigmentos fotossintetizantes. Níveis crescentes de $\mathrm{NaCl}$ reduziram a alocação de fitomassa e a densidade radicular do labe-labe cv. Rongai, e os teores de pigmentos clorofilianos do guandu cv. Caqui. O crescimento radicular e o teor de pigmentos clorofilianos de leguminosas forrageiras são alterados quando estas são cultivadas na presença de níveis crescentes de salinidade em solução nutritiva.

Palavras-chave adicionais: Cajanus cajan; Lablab purpureous; pigmentos fotossintéticos; raízes; salinidade.

\begin{abstract}
Salinity is a barrier to agricultural cultivation in areas where it is abundant concentration of minerals, particularly those that contain $\mathrm{Na}^{+}$and $\mathrm{Cl}^{-}$ions. The objective of this study was to evaluate root growth and chlorophyllian pigments levels of two forage legumes grown in the presence of increasing levels of salinity. The experiment was conducted in a growth chamber with temperature and light controlled. Seeds were sown in trays filled with moist sterile sand. After ten days of sowing the seedlings were transplanted to pots with nutrient solution. The experimental design was completely randomized in a factorial arrangement (2x6) with six replications. Treatments consisted of two grasses (pigeon pea cv. Caqui and labe-labe cv. Rongai) and six concentrations of $\mathrm{NaCl}(0,20$, $40,60,80$ and $120 \mathrm{mM}$ ) in nutrient solution. We evaluated the density and root biomass and chlorophyll content ' $a$ ', ' $b$ ', full and $a / b$ ratio. Data were subjected to analysis of variance, mean test and polynomial regression. Among the forages the labe-labe cv. Rongai expressed greater root growth and levels of photosynthetic pigments. $\mathrm{NaCl}$ increasing levels reduced the biomass allocation and root density of labe-labe cv. Rongai and the contents of chlorophyllian pigments in pigeon pea cv. Caqui. Root growth and chlorophyllian pigment content of forage legumes are changed when are grown in the presence of increasing levels of salinity in nutrient solution.
\end{abstract}

Additional keywords: Cajanus cajan; Lablab purpureous; photosynthetic pigments; roots; salinity. 


\section{Introdução}

As pastagens constituem o principal componente das dietas de ruminantes e fonte de alimentação mais econômica nos sistemas pecuários (Skonieski et al., 2011). No cenário agrícola brasileiro, essas plantas possuem significativo destaque, já que o nosso país é detentor do segundo maior rebanho comercial do mundo (Oliveira Júnior et al., 2012). O guandu (Cajanus cajan L. Millsp) e labe-labe (Lablab purpureus L. Sweet), pelo alto valor nutricional, são consideradas importantes leguminosas forrageiras para a alimentação animal (Vilela, 2005; Heinritz et al., 2012; Kambashi et al., 2014).

A salinização dos solos é um dos grandes problemas enfrentados em muitas regiões distribuídas em vastas áreas, nos diversos países (Uddin et al., 2011). Estima-se que mais de 800 milhões de hectares dos solos mundiais já possuam problemas de salinização, em razão, principalmente, da intensa evapotranspiração, baixas precipitações e irrigação (Rengasamy, 2010). Vários processos bioquímicos e fisiológicos são desencadeados em plantas sob estresse salino, interferindo no crescimento da parte aérea e das raízes, comportamento estomático e capacidade fotossintética (Nunkaewa et al., 2014), resultantes dos efeitos osmóticos dos sais e das características especificas dos íons $\mathrm{Na}^{+}$e $\mathrm{Cl}^{-}$(Nobre et al., 2010; Graciano et al., 2011). O estresse salino promove a inibição da enzima clorofilase, o que acarreta diminuição dos teores de clorofila e de seu precursor, o ácido 5-aminolevulinato (Santos, 2004; Qiu et al., 2014).

Além do mais, a atividade de várias enzimas fica comprometida pelo excesso de $\mathrm{Na}^{+}$, pois este metal compete com $0 \mathrm{~K}^{+}$pelo mesmo sítio ativo de enzimas, cujo cofator de ativação enzimática é o potássio (Freire et al., 2010; Silva et al., 2014), desencadeando distúrbios metabólicos com implicações negativas na fisiologia das plantas como um todo, uma vez que a salinidade afeta os teores de clorofilas e de carotenoides, além de reduzir a atividade da Rubisco em fixar gás carbônico (Lee et al., 2004; Jaleel et al., 2007).

Este cenário denota a importância do desenvolvimento de pesquisas, visando estudar as implicações dos íons salinos no metabolismo das plantas, sendo tais implicações passivas de serem estudadas através do crescimento e do teor de pigmentos fotossintetizantes. De fato, estudos dessa natureza podem ser esclarecedores, pois $\mathrm{NaCl}$ em excesso diminui de forma significativa altura, fitomassa aérea e radicular, teores de clorofilas, enzimas antioxidantes, além de elevar a produção de espécies reativas de oxigênio e a concentração de malondialdeído em plantas (Qiu et al., 2014).

Objetivou-se com este estudo avaliar o crescimento radicular e os teores de pigmentos clorofilianos de duas leguminosas forrageiras cultivadas na presença de níveis crescentes de salinidade em solução nutritiva.

\section{Material e métodos}

O experimento foi conduzido no Laboratório de Fisiologia Vegetal do Departamento de Biologia Aplicada à Agropecuária (DBAA), da Faculdade de Ciências Agrárias e Veterinárias (FCAV), Universidade Estadual Paulista (UNESP), Câmpus de Jaboticabal-SP. A semeadura foi realizada separadamente, em quatro bandejas preenchidas com areia estéril e umedecida com água destilada, as quais permaneceram em sala de crescimento à temperatura de $25^{\circ} \mathrm{C} \pm 1^{\circ} \mathrm{C}$, sob luminária com irradiância média de $190 \mu \mathrm{mol} \mathrm{m} \mathrm{m}^{-2} \mathrm{~s}^{-1}$ e fotoperíodo de 12 horas. Aos 10 dias após a semeadura (DAS), as plântulas foram transferidas para as respectivas unidades experimentais, constituídas por vasos de plástico com capacidade de $190 \mathrm{~mL}$. O delineamento experimental foi o inteiramente casualizado, em esquema fatorial $2 \times 6$, com os fatores espécies constituídos por plantas de guandu cv. Caqui e labe-labe cv. Rongai, e a salinidade simulada por $\mathrm{NaCl}$ nas concentrações de 0; 20; 40; 60; 80 e 120 mM. Cada tratamento foi constituído por quatro repetições, em um total de 48 parcelas experimentais, em solução nutritiva (Gonela, 1999). Na extremidade superior de cada vaso, foi ajustado um disco de isopor branco com um furo central no qual a plântula, de cada espécie e com 10 DAS, foi inserida com a parte aérea exposta ao ambiente externo, e o sistema radicular imerso na solução nutritiva de Hoagland \& Arnon (1950). O pH da solução nutritiva foi monitorado a cada dois dias, o qual foi mantido em $6,1 \pm 0,1$, utilizando-se de $\mathrm{NaOH} 0,1 \mathrm{~N}$. As soluções foram aeradas por todo 0 período experimental. Inicialmente, as plântulas foram cultivadas em solução nutritiva com metade da força iônica, por cinco dias. Em seguida, a força iônica foi elevada a 100\% e mantida até o final do experimento. As plântulas das espécies, com 20 DAS, foram submetidas aos níveis crescentes de salinidade correspondentes aos tratamentos. Aos 30 DAS, para a obtenção dos teores de clorofilas, conforme metodologia proposta por Arnon (1949), foram coletadas amostras foliares, pesando-se $0,5 \mathrm{~g}$ de tecido vegetal, o qual foi macerado com $5 \mathrm{~mL}$ de acetona a $80 \%(\mathrm{v} / \mathrm{v})$. Após a maceração, o material foi filtrado a vácuo, e o volume final, completado até $50 \mathrm{~mL}$ com acetona. Os extratos obtidos foram submetidos às leituras de absorbância, utilizando-se do espectrofotômetro Beckman DU 640, nos comprimentos de onda de $663 \mathrm{~nm}$ para clorofila 'a' (Chl a), $645 \mathrm{~nm}$ para 'b' (Chl b) e $652 \mathrm{~nm}$ para clorofila total (Chl t). Os teores de clorofilas, expressos em $\mathrm{mg} \mathrm{g}^{-1}$ de massa fresca, foram calculados por meio das equações a seguir:

Chl $\mathrm{a}=\left(12,7 \times \mathrm{A}_{663}-2,69 \times \mathrm{A}_{645}\right) \times \mathrm{V} /(1000 \times \mathrm{W}) ;$

Chl $b=\left(22,9 \times A_{645}-4,68 \times A_{663}\right) \times V /(1000 \times W) ;$

Chl $t=\left(A_{652} \times 1000\right) / 34,5 \times(V /(1000 \times W))$;

Razão Chl a/Chl b $=\left(\left(4,70 \times A_{663}-A_{645} \times 1000\right) /\right.$ $\left./\left(4,87 \times A_{645}-A_{663}\right)\right) \times 0,574$. 
Em que: $A=$ absorbância (nm); $V=$ volume final do extrato (acetona a $80 \%$ + clorofila), e $\mathrm{W}=$ massa fresca das amostras $(\mathrm{g})$. Foi determinado, também, o crescimento radicular, mediante a densidade $(\mathrm{mm}$ de raiz $\mathrm{cm}^{-3}$ de solução nutritiva), utilizando-se do sistema de análise de imagens da Delta-T Devices LTD (Harris \& Campbell, 1989). Concomitantemente, o material vegetal foi coletado, acondicionado em sacos de papel e levados à estufa de circulação de ar, à temperatura de $65^{\circ} \mathrm{C}$, por 72 horas, para secagem e posterior mensuração da massa de matéria seca obtida, utilizando-se de balança analítica com precisão de $\pm 0,001 \mathrm{~g}$. Os dados obtidos foram submetidos à análise de variância, e as médias de espécies, comparadas pelo teste de Tukey, a $5 \%$ de probabilidade de erro. A análise da regressão polinomial foi utilizada para o desdobramento dos graus de liberdade das concentrações de $\mathrm{NaCl}$ (Banzatto \& Kronka, 2006).

\section{Resultados e discussão}

Com base nos resultados obtidos para os fatores isolados, constatou-se que houve diferenças significativas $(p<0,01)$ entre as espécies, em todas as variáveis avaliadas nesta pesquisa. Verificou-se, também, que os níveis de $\mathrm{NaCl}$ promoveram diferenças expressivas $(p<0,01)$ nos níveis de clorofila 'a', relação clorofila $a / b$ e massa seca radicular das espécies. Analisando-se os efeitos conjuntos dos fatores espécie e níveis de salinidade, verificou-se que houve interação significativa $(p<0,01)$ entre os mesmos para os teores de clorofilas 'a', 'b', total e relação clorofila a/b (Tabela 1).

Comparando-se as espécies estudadas, independentemente dos níveis de $\mathrm{NaCl}$, é possível verificar que $\mathrm{o}$ Labe-labe cv. Rongai acumulou maiores teores de clorofilas 'a' $\left(0,6 \mathrm{mg} \mathrm{g}^{-1}\right)$, 'b' $\left(0,5 \mathrm{mg} \mathrm{g}^{-1}\right)$, total $\left(1,0 \mathrm{mg} \mathrm{g}^{-1}\right)$ e relação a/b $\left(1,8 \mathrm{mg} \mathrm{g}^{-1}\right)$, de modo que estes valores foram 22; 28 ; 25 e $22 \%$, respectivamente, superiores aos teores verificados na leguminosa forrageira Guandu cv. Caqui para as mesmas variáveis. Resultados semelhantes foram evidenciados para as variáveis massa seca e densidade radicular, sendo os valores observados $(0,05 \mathrm{~g})$ e $\left(26,6 \mathrm{~mm} \mathrm{~cm}^{-3}\right)$ no Labe-labe cv. Rongai 60 e $66 \%$ superiores aos evidenciados no Guandu cv. Caqui $(0,02 \mathrm{~g})$ e $\left(9,10 \mathrm{~mm} \mathrm{~cm}^{-3}\right)$ para as respectivas variáveis (Tabela 1 ).

Tabela 1 - Resumo das análises de variância e testes de Tukey dos teores de clorofilas a, b, total e razão clorofila a/b, massa seca e densidade radicular de plantas de guandu cv. Caqui e labe-labe cv. Rongai, submetidas a níveis crescentes de $\mathrm{NaCl}$. Summary of analysis of variance and Tukey tests the levels of chlorophyll $a, b$, and total, chlorophyll a/b ratio, root dry mass and root density of pigeonpea plants cv. Caqui and labe-labe cv. Rongai subjected to increasing levels of $\mathrm{NaCl}$.

\begin{tabular}{|c|c|c|c|c|c|c|c|}
\hline \multirow[b]{2}{*}{ Fontes de variação } & \multirow[b]{2}{*}{ G.L. } & \multicolumn{6}{|c|}{ Quadrados Médios } \\
\hline & & $\begin{array}{c}\text { Chl a } \\
\left(\mathrm{mg} \mathrm{g}^{-1}\right)\end{array}$ & $\begin{array}{c}\text { Chl b } \\
\left(\mathrm{mg} \mathrm{g}^{-1}\right)\end{array}$ & $\begin{array}{l}\text { Chl (a+b) } \\
\left(\mathrm{mg} \mathrm{g}^{-1}\right)\end{array}$ & $\begin{array}{l}\mathrm{Chl} \mathrm{a/b} \\
\left(\mathrm{mg} \mathrm{g}^{-1}\right)\end{array}$ & $\begin{array}{c}\text { MSR } \\
\left(\text { g planta }^{-1}\right)\end{array}$ & $\begin{array}{c}\text { DRA } \\
\left(\mathrm{mm} \mathrm{cm}^{-3}\right)\end{array}$ \\
\hline Espécie (E) & 1 & $0,2198^{* *}$ & $0,2655^{\star *}$ & $0,8011^{* *}$ & $1,8530^{* *}$ & $0,0062^{* *}$ & $3673,6841^{* *}$ \\
\hline Salinidade (S) & 5 & $0,0763^{* *}$ & ${ }^{(1)} 0,0304 \mathrm{~ns}$ & ${ }^{(1)} 0,1323 \mathrm{~ns}$ & $0,6351^{* *}$ & $0,0003^{\star \star}$ & $41,9878 \mathrm{~ns}$ \\
\hline Interação Ex S & 5 & $0,1207^{* *}$ & $0,1207^{\star *}$ & $0,3964^{\star *}$ & $1,0637^{* *}$ & $0,0001 \mathrm{~ns}$ & $14,9878 \mathrm{~ns}$ \\
\hline Resíduo & 36 & 0,0203 & 0,0148 & 0,0547 & 0,1730 & 0,0001 & 17,3643 \\
\hline \multicolumn{2}{|l|}{ C.V. (\%) } & 25,9016 & 26,4898 & 26,2260 & 25,9833 & 22,8113 & 23,3399 \\
\hline \multicolumn{2}{|l|}{ Espécie } & \multicolumn{6}{|c|}{${ }^{(2)}$ Médias e teste de Tukey } \\
\hline \multicolumn{2}{|l|}{ Guandu cv. Caqui } & $0,4820 \mathrm{~b}$ & $0,3847 \mathrm{~b}$ & $0,7623 \mathrm{~b}$ & $1,4045 \mathrm{~b}$ & $0,0255 \mathrm{~b}$ & 9,1053 b \\
\hline \multicolumn{2}{|l|}{ Labe-labe cv. Rongai } & $0,6174 a$ & $0,5334 a$ & $1,0207 a$ & $1,7975 a$ & $0,0482 a$ & $26,6055 a$ \\
\hline \multicolumn{2}{|l|}{ D.M.S. } & 0,0834 & 0,0712 & 0,1370 & 0,2437 & 0,0049 & 2,4412 \\
\hline
\end{tabular}

ns: não significativo $(p>0,05) ;{ }^{*}$ : significativo $(p<0,05) ;{ }^{* *}$ : significativo $(p<0,01)$; G.L.: graus de liberdade; C.V.: coeficiente de variação; ${ }^{(1)}$ Valor de $F>2,0$ em Clorofila b com $F=2,0530$ e em Clorofila total $(a+b)$ com $F=2,4210$ considera-se significativo, devido ao fator de predominância. ${ }^{(2)}$ Médias na coluna, seguidas de mesma letra, não diferem entre si, pelo teste de Tukey ( $p>0,05)$; D.M.S.: diferença mínima significativa.

As diferenças verificadas entre as forrageiras estudadas são decorrentes de características genéticas particulares de cada espécie. Esta informação é ratificada por Barro et al. (2008) e Kirchner et al. (2010) que, em estudos com forrageiras de inverno, também verificaram diferenças entre espécies para variáveis bioquímicas. Em relevante contribuição acerca do crescimento de plantas forrageiras, Barbero et al. (2013) reportam que diferenças constatadas entre espécies são atribuídas a fatores genéticos intrínsecos.
Os teores de clorofila a e b (Figura 1A) ajustaram-se à tendência linear, evidenciando redução com o incremento dos níveis de $\mathrm{NaCl}$ nas plantas de Guandu cultivar Caqui, sendo o mesmo padrão de resposta verificado para as variáveis clorofila total e razão da clorofila a/b (Figura 1B). Decréscimos nos teores de pigmentos cloroplastidiais foram observados em várias culturas expostas ao estresse salino, como mamona (Pinheiro et al., 2008), melão (Aragão et al., 2009) e pinhão-manso (Silva et al., 2010). 

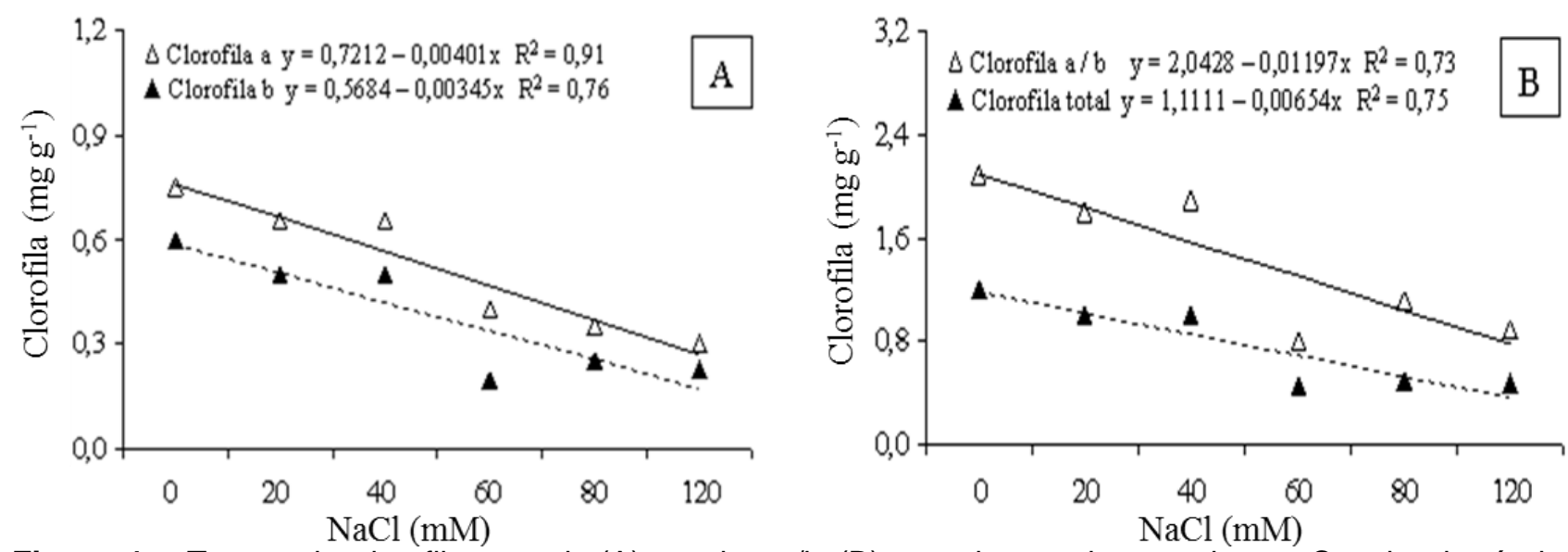

Figura 1 - Teores de clorofilas a e $b(A)$, total e $a / b(B)$ em plantas de guandu cv. Caqui sob níveis crescentes de $\mathrm{NaCl}$. Content of chlorophyll $a$ and $b(A)$, full and $a / b(B)$ in plants of pigeonpea $\mathrm{cv}$. Caqui subjected to increasing levels of $\mathrm{NaCl}$.

Redução nos teores de pigmentos cloroplastidiais pode resultar tanto da degradação como do decréscimo da síntese de clorofilas e o possível envolvimento da enzima clorofilase na degradação de clorofilas em folhas sob processo de senescência, induzido por sais em plantas, uma vez que foram observados incrementos na atividade desta enzima em tecidos foliares de girassol submetido a salinidade (Santos, 2004). Acrescente-se que, em condições salinas supraótimas, a planta produz espécies reativas de oxigênio (ROS), o que de fato pode ser verificado pelas mudanças na atividade das enzimas antioxidantes: catalase (CAT), ascórbico peroxidase $(\mathrm{APx})$, glutationa redutase (GR) e superóxido dismutase (SOD), envolvidas na detoxificação de ROS, frequentemente observadas em plantas sob estresse salino (Nunkaewa et al., 2014). Entretanto, redução nos teores de pigmentos fotossintéticos, em plantas cultivadas sob salinidade, pode ser uma estratégia de proteção e/ou aclimatação em que a redução no gasto de energia, esqueletos de carbono e nutrientes necessários à síntese de clorofila pode favorecer outros processos fisiológicos associados à atenuação do estresse salino (Chaves et al., 2008).

$\mathrm{O}$ incremento nos níveis de $\mathrm{NaCl}$ até ao limite de $51,8 \mathrm{mM}$ promoveu aumento de $15 \%$ na massa seca radicular da forrageira leguminosa labe-labe cv. Rongai, comparando-se com plantas conduzidas na ausência de salinidade. Porém, valores superiores promoveram redução expressiva de $28, \%$ na fitomassa radicular até o nível de $120 \mathrm{mM}$ de $\mathrm{NaCl}$ (Figura 2A). Embora não tenha sido constatado efeito significativo do fator salinidade para a variável densidade radicular, desdobrando-se os graus de liberdade por meio de regressão polinomial, verificou-se ajuste linear decrescente das médias em função do aumento dos níveis de $\mathrm{NaCl}$, sendo registrado decréscimo de $27 \%$ no nível máximo de $120 \mathrm{mM}$, quando comparado com as plantas-controle (Figura 2B).

Os principais íons salinos, $\mathrm{Na}^{+}$e $\mathrm{Cl}^{-}$, podem afetar o sistema radicular diminuindo a absorção de nutrientes por meio da interação competitiva ou afetando a seletividade da membrana. Por exemplo, um elevado nível de $\mathrm{Na}^{+}$induz deficiencia de $\mathrm{Ca}^{2+}$ e $\mathrm{K}^{+}$. A salinidade, também, induz o estresse osmótico, dificultando a absorção de água pelas raizes. De fato, estes danos provocados pelos íons salinos nos tecidos das plantas podem ser explicados pelo desequilibrio nas proporcções $\mathrm{Na}^{+} / \mathrm{K}^{+}$e $\mathrm{Na}^{+} / \mathrm{Ca}^{2+}$, devido ao acúmulo de íons $\left(\mathrm{Na}^{+}\right.$e $\left.\mathrm{Cl}^{-}\right)$presentes em solos salinizados e em água de irrigação com elevada salinidade (Rodrigues et al., 2014).

A redução do potencial hídrico, induzida pelo sal, bem como, os efeitos citotóxicos dos íons $\mathrm{Na}^{+}$e $\mathrm{Cl}^{\prime}$ são responsáveis pela redução na fitomassa e na densidade radicular das plântulas (Gordin et al., 2012; Maia et al., 2012). Esta informação é ratificada por Monteiro et al. (2014) ao relatarem que em situações de toxidez por $\mathrm{Na}^{+}$e $\mathrm{Cl}^{-}$, a degradação de compostos celulares e a síntese de metabólitos indesejáveis podem promover redução drástica do crescimento. Estes pesquisadores verificaram expressiva redução na massa da matéria seca de raízes das cultivares de guandu 'BRS Mandarim' e 'Caqui' sob níveis crescentes de $\mathrm{NaCl}$.

É importante salientar que vários mecanismos de proteção são ativados nas plantas em resposta a condições adversas de crescimento. O ajuste osmótico constitui-se em um dos mecanismos fisiológicos mais eficazes para a manutenção da turgescência celular, sob condições de salinidade no solo (Marijuan \& Bosch, 2013), de modo que o aumento verificado na fitomassa radicular até o limite de $51,8 \mathrm{mM}$ pode indicar estratégia de defesa natural da planta contra o estresse salino, notadamente pelo alongamento da raiz em busca de ambiente isento de salinidade elevada. Por outro lado, Pinheiro et al. (2013) reportam que níveis elevados de salinidade diminuem o gradiente de potencial entre a solução de cultivo e a raiz, reduzindo a permeabilidade radicular, propiciando aumento no acúmulo de sais no tecido vegetal, inibindo os processos metabólicos e fisiológicos, o que explica a redução no crescimento radicular das plantas sob concentrações salinas 
superiores a 51,8 mM. De fato, esta informação é ratificada por Ferraz et al. (2011), que ao estudarem plântulas de algodoeiro sob salinidade, verificaram aumento no acúmulo de fitomassa até o nível de condutividade elétrica de $2,8 \mathrm{dS} \mathrm{m}^{-1}$, com ajuste quadrático, ocorrendo redução expressiva a partir deste ponto. Estes pesquisadores reportam que o

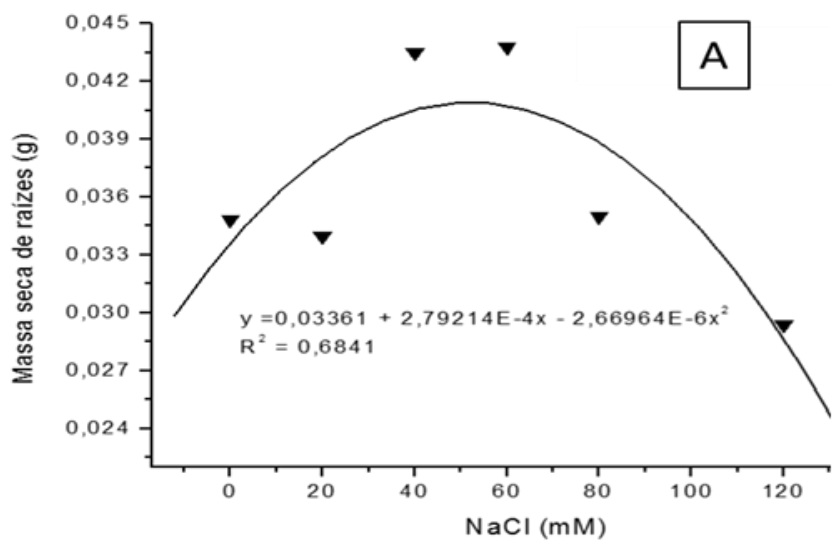

Figura 2 - Massa seca $(A)$ e densidade radicular crescentes de $\mathrm{NaCl}$. Dry mass $(A)$ and root density levels of $\mathrm{NaCl}$.

\section{Conclusões}

$\mathrm{O}$ crescimento radicular e o teor de pigmentos clorofilianos de leguminosas forrageiras são alterados quando estas são cultivadas na presença de níveis crescentes de salinidade em solução nutritiva.

\section{Referências}

Aragão CA, Santos JS, Queiroz SOP, Dantas BF (2009) Avaliação de cultivares de melão sob condições de estresse salino. Revista Caatinga 22(2):161-169.

Arnon DI (1949) Copper enzymes in chloroplasts. Phenol oxidases in Beta vulgares. Plant Physiology 24(1):1-15.

Banzatto DA, Kronka SN (2006) Experimentação agrícola. 4.ed. Jaboticabal: FUNEP, 2006 237p.

Barbero LM, Prado TF, Basso KC, Lima LA, Motta KM, Kruger BC, Martins Neto LR, Silva GAS (2013) Análise de crescimento em plantas forrageiras aplicada ao manejo de pastagens. Veterinária Notícias 19(2):71-85.

Barro RS, Saibro JC, Medeiros RB, Silva JLS (2008) Rendimento de forragem e valor nutritivo de gramíneas anuais de estação fria submetidas a sombreamento por Pinis elliottii e ao sol pleno. Revista Brasileira de Zootecnia 37(10):1.721-1.727.

Chaves MM, Flexas J, Pinheiro C (2008) Photosynthesis under drought and salt stress: regulation mechanisms from whole plant to cell. Annals of Botany 125(4):1-10.

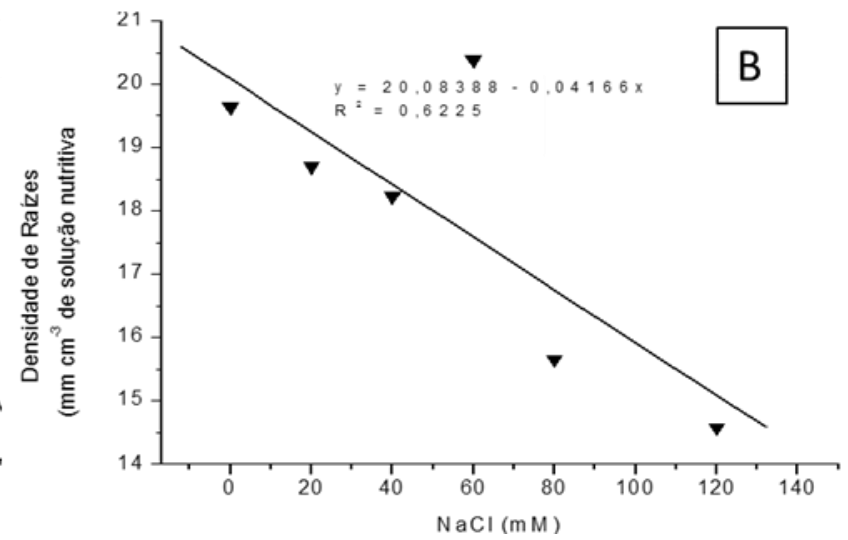

aumento parcial na fitomassa radicular deve-se ao fato de os íons $\mathrm{Na}^{+}$e $\mathrm{Cl}^{-}$desempenharem importantes funções metabólicas na planta, além de a cultura ser considerada tolerante à salinidade, fato também mencionado por Oliveira et al. (2012).

(B) em plantas de labe-labe cv. Rongai sob níveis (B) of labe-labe cv. Rongai plants subjected increasing Ferraz RLS, Beltrão NEM, Magalhães ID, Rocha MS, Melo AS (2011) Aspectos morfológicos e bioquímicos em plântulas de algodoeiro 'BRS Topázio' sob salinidade. Revista Brasileira de Oleaginosas e Fibrosas 15(2):53-61.

Freire ALO, Rodrigues TJD, Miranda JRP (2010) Crescimento e nutrição de plantas de leucena (Leucaena leucocephala (Lam.) R. de Vit) sob salinidade. Revista Caatinga 23(4):1-6.

Gonela A (1999) Tolerância ao NaCl em variedades de Stylosantes guianensis (Aubl.) Sw. UNESP (Dissertação de mestrado em Agronomia).

Gordin CRB, Marques RF, Masseto TE, Souza LCF (2012) Estresse salino na germinação de sementes e desenvolvimento de plântulas de níger (Guizotia abyssinica (L.f.) Cass.). Acta Botanica Brasilica 26(4):966-972.

Graciano ESA, Rejane JMC, Nogueira RJMC, Lima DRM, Pacheco CM, Santos RC (2011) Crescimento e capacidade fotossintética da cultivar de amendoim BR 1 sob condições de salinidade. Revista Brasileira de Engenharia Agrícola e Ambiental 15(8):794-800.

Harris GA, Campbell GS (1989) Automated quantification of roots using a simple image analyser. Agronomy Journal 81(6):935-938.

Heinritz SN, Martens SD, Avila P, Hoedtke S (2012) The effect of inoculant and sucrose addition on the silage quality of tropical forage legumes with varying ensilability. Animal Feed Science and Technology 174(4):201-210. 
Hoagland D, Arnon DI (1950) The water culture method for growing plants without soil. California Agriculture Experimental Station Circular, 347p.

Jaleel CA, Gopi R, Manivannan P, Panneerselvan R (2007) Antioxidative potentials as a protective mechanism in Catharanthus roseus (L.) G. Don. plants under salinity stress. Turkish Journal of Botany 31(3):245-251.

Kambashi B, Picron P, Boudry C, Théwis A, Kiatoko H, Bindelle $J$ (2014) Nutritive value of tropical forage plants fed to pigs in the Western provinces of the Democratic Republic of the Congo. Animal Feed Science and Technology 191(5):47-56.

Kirchner R, Soares AB, Sarto LR, Adami PR, Migliorini F, Fonseca L (2010) Desempenho de forrageiras hibernais sob distintos níveis de luminosidade. Revista Brasileira de Zootecnia 39(11):2.371-2.379.

Lee G, Carrow RN, Duncan RR (2004) Salinity tolerance of selected seashore Paspalums and Bermuda grasses: root and verdure responses and criteria. Horticulturae Science 39(5):1.143-1.147.

Maia JM, Ferreira-Silva SL, Voigt EL, Macêdo CEC de, Ponte LFA, Silveira JAG (2012) Atividade de enzimas antioxidantes e inibição do crescimento radicular de feijão-caupi sob diferentes níveis de salinidade. Acta Botanica Brasilica 26(2):342-349.

Marijuan MP, Bosch SM (2013) Ecophysiology of invasive plants: osmotic adjustment and antioxidants. Trends in Plant Science 18(12):660-666.

Monteiro JG, Cruz FJR, Nardin MB, Santos DMMS (2014) Crescimento e conteúdo de prolina em plântulas de guandu submetidas a estresse osmótico e à putrescina exógena. Pesquisa Agropecuária Brasileira 49(1):18-25.

Nobre RG, Gheyi HR, Correia KG, Soares FAL Andrade LO (2010) Crescimento e floração do girassol sob estresse salino e adubação nitrogenada. Revista Ciência Agronômica 41(3):358-365.

Nunkaewa $T$, Kantachote D, Kanzaki $H$, Nitoda $T$, Ritchie RJ (2014) Effects of 5-aminolevulinic acid (ALA)-containing supernatants from selected Rhodopseudomonas palustris strains on rice growth under $\mathrm{NaCl}$ stress, with mediating effects on chlorophyll, photosynthetic electron transport and antioxidative enzymes. Electronic Journal of Biotechnology 17(1):19-26.

Oliveira FA, Medeiros JF, Oliveira FRA, Freire AG, Soares LCS (2012) Produção do algodoeiro em função da salinidade e tratamento de sementes com regulador de crescimento. Revista Ciência Agronômica 43(2):279-287.

Oliveira Júnior MB, Vanderlei DR, Moraes WS, Brandspim DF, Mota RA, Oliveira AAF, Medeiros ES, Pinheiro Júnior JW (2012) Fatores de risco associados à mastite bovina na microrregião Garanhuns, Pernambuco. Pesquisa Veterinária Brasileira 32(5):391-395.
Pinheiro GG, Zanotti RF, Paiva CEC, Lopes JC, Gai ZT (2013) Efeito do estresse salino em sementes e plântulas de feijão-guandu. Enciclopédia Biosfera 9(16):901-912.

Pinheiro HA, Silva JV, Endres L, Ferreira VM, Câmara CA, Cabral FF, Oliveira JF, Carvalho LWT, Santos JM, Santos Filho BG (2008) Leaf gas exchange, chloroplastic pigments and dry matter accumulation in castor bean (Ricinus communis L.) seedlings subjected to salt stress conditions. Industrial Crops and Products 27(3):385-392.

Qiu ZB, Guo J, Jhu AJ, Zhang L, Zhang MM (2014) Exogenous jasmonic acid can enhance tolerance of wheat seedlings to salt stress. Ecotoxicology and Environmental Safety 104(6):202-208.

Rengasamy P (2010) Soil processes affecting crop production in salt-affected soils. Functional Plant Biology 37(7):613-620.

Rodrigues CRF, Silva EN, Moura RM, Anjos DC, Hernandez FFF, Viégas RA (2014) Physiological adjustment to salt stress in $R$. communis seedlings is associated with a probable mechanism of osmotic adjustment and a reduction in water lost by transpiration. Industrial Crops and Products 54(3):233-239.

Santos CV (2004) Regulation of chlorophyll biosynthesis and degradation by salt stress in sunflower leaves. Scientia Horticulturae 103(1):93-99.

Silva EN, Ribeiro RV, Ferreira-Silva SL, Viégas RA, Silveira JAG (2010) Comparative effects of salinity and water stress on photosynthesis, water relations and growth of Jatropha curcas plants. Journal of Arid Environments 74(10):1.130-1.137.

Silva IP, Rodas CL, Ferreira ED, Carvalho JG (2014) Crescimento e nutrição de mudas de pinhão-manso influenciados pela substituição do potássio pelo sódio. Revista Caatinga 27(1):194-199.

Skonieski FR, Viégas J, Bermudes RF, Nörnberg JL, Ziech MF, Costa OAD, Meinerz GR (2011) Composição botânica e estrutural e valor nutricional de pastagem de azevém consorciadas. Revista Brasileira de Zootecnia 40(3):550-556.

Uddin M, Juraime AS, Ismail MR, Othman R, Rahim AA (2011) Relative salinity tolerance of warm season turf grass species. Journal of Environment Biology 32(3):309-312.

Vilela H (2005) Pastagem: Seleção de plantas forrageiras, implantação e adubação.1.ed. Viçosa, MG: Aprenda fácil, 283p. 